\title{
Thyroid hormone regulation of prohormone convertase 1 (PC1): regional expression in rat brain and in vitro characterization of negative thyroid hormone response elements
}

\author{
X Shen ${ }^{1}, Q-L_{\text {Li }}{ }^{1}$, G A Brent ${ }^{2}$ and T C Friedman ${ }^{1,3}$ \\ ${ }^{1}$ Division of Endocrinology, Charles R Drew University of Medicine \& Sciences-UCLA School of Medicine, Los Angeles, CA 90059, USA \\ 2Division of Endocrinology, Department of Medicine, West Los Angeles VA Medical Center, Los Angeles, CA 90073, USA \\ ${ }^{3}$ Division of Endocrinology, Department of Medicine, Cedars-Sinai Medical Center, Los Angeles, CA 90048, USA \\ (Requests for offprints should be addressed to T C Friedman, Charles R Drew University of Medicine \& Sciences, Division of Endocrinology, $1731 \mathrm{E}$ \\ 120th Street, Los Angeles, CA 90059, USA; Email: tefriedm@cdrewu.edu (electronic reprints will be sent by email)) \\ (Q-L Li is now at Charles R Drew University of Medicine \& Sciences, Department of Anesthesia, 1731 E 120th Street, Los Angeles, CA 90059, USA) \\ (X Shen is now at South Baylo University, Medical Research Center, 1126 N Brookhurst Street, Anaheim, CA 92801, USA)
}

\begin{abstract}
Most pro-neuropeptides are processed by the prohormone convertases, PC1 and PC2. We previously reported that changes in thyroid status altered anterior pituitary PC1 mRNA and this regulation was due to triiodothyronine $\left(T_{3}\right)$-dependent interaction of thyroid hormone receptor (TR) with negative thyroid hormone response elements (nTREs) contained in a large region of the human PC1 promoter. In this study, we demonstrated that hypothyroidism stimulated, while hyperthyroidism suppressed, PC1 mRNA levels in rat hypothalamus and cerebral cortex, but not in hippocampus. In situ hybridization was used to confirm real-time PCR changes and localize the regulation within the hypothalamus and cortex. Using a human PC1 (hPC1) promoter construct (with and without deletions in two regions that each contain a negative TRE) transiently transfected into GH3 cells, we found that $T_{3}$ negatively regulated $h P C 1$ promoter activity, and this regulation required both of these two regions. Electrophoretic mobility shift assays (EMSAs) using purified thyroid hormone receptor $\alpha 1$ (TR $\alpha 1)$ and retinoid $X$ receptor $\beta$ (RXR $\beta$ ) proteins demonstrated that RXR and TR $\alpha$ both bound the PC1 promoter. Addition of TR $\alpha 1 / R X R \beta$ to the wild-type PC1 probe demonstrated binding as both homodimers and a heterodimer. EMSAs with oligonucleotides containing deletion mutations of the putative nTREs demonstrated that the proximal nTRE binds more strongly to TR and RXR than the distal nTRE, but that both regions exhibit specific binding. We conclude that there are multiple novel TRE-like sequences in the hPC1 promoter and that these regions act in a unique manner to facilitate the negative effect of thyroid hormone on PC1.
\end{abstract}

Journal of Molecular Endocrinology (2004) 33, 21-33

\section{Introduction}

Prohormone convertases (PCs), are involved in the tissue-specific endoproteolytic processing of prohormones and neuropeptide precursors within the secretory pathway and are thought to be responsible for the cleavage of many prohormones at paired basic residues to generate bioactive hormones (Steiner 1998, Seidah \& Chretien 1999). In mammals, seven prohormone and proprotein-processing enzymes responsible for this cleavage have been molecularly characterized. PG1 and PC2 are specifically found in neural and endocrine cells equipped with a regulatory secretory pathway (Bloomquist et al. 1991, Day et al. 1992, Seidah \& Chretien 1999) and are the likely enzymes involved in prohormone/ pro-neuropeptide processing (Seidah \& Chretien 1999). In the rat pituitary, PG1 is present primarily in the anterior lobe with lower levels in the posterior and intermediate lobes, while PC2 is found 
predominantly in the intermediate lobe (Seidah et al. 1991). Pituitary PG1 and PC2 mRNA levels have been found to be regulated by dopamine agonists and antagonist (Birch et al. 1991, Bloomquist et al. 1991, Day et al. 1992).

The important role of PC1 and PC2 in hormonal biosynthesis has been elucidated by studies of PG1 and PG2 null mice and in a patient with defective PG1. PG1 null mice are short due to impaired pro-growth hormone-releasing hormone (proGHRH) processing and are hyperglycemic due to impaired proinsulin processing ( $\mathrm{Zhu}$ et al. 2002a,b). PC2 null mice have absent proglucagon processing and impaired proinsulin processing and are hypoglycemic (Furuta et al. 1997). In addition, proenkephalin and prodynorphin processing are blocked in these mice (Berman et al. 2000, Laurent et al. 2004). A patient lacking PC1 had severe childhood-onset obesity, post-prandial hypoglycemia, infertility, and low levels of adrenocorticotropic hormone (ACTH) and cortisol with elevated levels of pro-opiomelanocortin (POMG) (O'Rahilly et al. 1995, Jackson et al. 1997).

Thyroid hormone regulates target gene expression by binding with nuclear thyroid hormone receptors (TRs), which are ligand-activated transcription factors. Thyroid hormone acts through TRs at the transcriptional level to regulate many genes such as thyrotropin-releasing hormone (TRH), thyroid-stimulating hormone (TSH), growth hormone $(\mathrm{GH})$ and $\alpha$-myosin heavy chain (Lazar 1993). Triidothyronine $\left(\mathrm{T}_{3}\right)$ mediates transcriptional regulation through interactions in the promoter region of target genes bearing consensus DNA sequences, referred to as thyroid hormone response elements (TREs) (Lazar 1993). Heterodimerization between $\mathrm{TR}$ and retinoid $\mathrm{X}$ receptor (RXR) usually augments the ligand-dependent stimulation or repression (Lazar 1993). However, in a few TREs, such as the one in human type-1 deiodinase promoter, RXR-independent mechanisms are involved in thyroid hormone regulation (Toyoda et al. 1995).

Limited studies of the regulation of processing enzymes by thyroid status have been performed in the rat pituitary. Rats made hypothyroid by thyroidectomy or 6-n-propyl-2-thiouracil (PTU) treatment had an increase in anterior pituitary PC1, PC2 (Day et al. 1992) and peptidylglycine alpha-amidating monooxygenase (PAM) (a processing enzyme involved in amidation) mRNA levels
(Ouafik et al. 1990), and a decrease in paired basic amino acid converting enzyme 4 (PACE4; a more ubiquitously distributed PG) mRNA levels (Johnson et al. 1994). Rats made hyperthyroid by daily injection of thyroxine $\left(\mathrm{T}_{4}\right)$ showed decreased anterior pituitary PG1, PG2 and PAM mRNA levels, and increased PACE4 mRNA levels (Day et al. 1992, Johnson et al. 1994).

We have previously shown that $\mathrm{T}_{3}$ negatively regulates both $\mathrm{PC} 1$ and $\mathrm{PC} 2$ in the rat anterior pituitary and in GH3 cells (Li et al. 2000, 2001). We also localized regions on both human promoters which contain putative negative TREs (nTREs) (Li et al. 2000, 2001). In this paper, we first studied the in vivo regulation of PCl mRNA by thyroid status in different regions of rat brain using in situ hybridization and real-time PGR. In order to address the mechanism of $\mathrm{T}_{3}$ regulation of the $\mathrm{PCl}$ gene at the promoter level, we used GH3 cells. This rat sommatotroph cell line expressing endogenous TRs (Hodin et al. 1989) has been widely used to study $\mathrm{T}_{3}$ regulation of both endogenous (Misiti et al. 1998) and exogenous (Hooi et al. 1997) genes. We used human PCl (hPGl) promoter-luciferase constructs and electrophoretic mobility shift assays (EMSAs) to identify two regions in the PC1 promoter that are both necessary for negative regulation by $T_{3}$.

\section{Materials and methods}

\section{Animals and treatments}

Adult male Sprague-Dawley rats (8 weeks old, 250-270 g) were housed in a room with controlled light, temperature and humidity. Three groups of six animals each were treated as follows: control (euthyroid) group, implantation of placebo with normal chow; hyperthyroid group, implantation of thyroid hormone $\mathrm{T}_{4}$ (L-thyroxine) pellet $(15 \mathrm{mg}$ ) (Innovative Research of America, Sarasota, FL, USA) with normal chow; hypothyroid group, implantation of placebo with chow containing low iodine and $0 \cdot 15 \%$ PTU (Harlan Teklad, Madison, WI, USA). Animals had free access to food and water; they were killed at 21 days after treatment and plasma was immediately collected.

Rat serum TSH levels were determined using a highly sensitive double-antibody method, developed by A F Parlow, Director of the National Hormone \& Pituitary Program (Harbor-UCLA 
Medical Center, Torrance, CA, USA; parlow@ humc.edu), similar to that described for measuring mouse TSH (Schneider et al. 2001). The assay used highly purified rat TSH as the iodinated ligand, a guinea-pig anti-rat TSH at a final tube dilution of 1:500 000 as the primary antibody, and a partially purified extract of rat pituitary containing TSH as the reference preparation. Cross-reactivity of either highly purified rat follicle-stimulating hormone (FSH) or rat luteinizing hormone (LH) in this mouse TSH RIA was less than 1\%. Displacement curves obtained by testing sera of hypothyroid rats in graded dilutions did not depart significantly from parallelism with displacement curves for the reference preparation. Recovery of exogenous rat TSH activity added to rat serum was $80-100 \%$. All sera were assayed for TSH concentrations by a tester who had no knowledge of the treatment status of the rats.

\section{Plasmid constructs and luciferase assay}

The wild-type human PCl (hPC1) promoter sequence and plasmid construct have been described previously (Li et al. 2001). Briefly, the wild-type hPGl luciferase fusion gene expression plasmid was constructed by subcloning hPC1 promoter DNA comprising the region of -82 to $+216 \mathrm{bp}$ (numbers relative to the primary transcription start site (TSS)) into the pGL2-basic plasmid (Promega, Madison, WI, USA) which was then used for transfection into GH3 cells. Mutations of the proximal promoter elements were generated by the oligonucleotide-directed mutagenesis method, which was performed using $P f u$ DNA polymerase. Following temperature cycling and primer extension, the products were treated with DpnI and the desired mutations were then transformed into Escherichia coli XL 1-Blue supercompetent cells. Each hPCl mutation was confirmed by sequencing.

\section{Cell culture and transfection}

GH3 cells (rat sommatotroph cells) were obtained from the American Type Culture Collection (Rockville, MD, USA) and were maintained at $37^{\circ} \mathrm{C}$ and $5 \% \mathrm{CO}_{2}$ in Dulbecco's modified Eagle's medium (DMEM) with 10\% fetal bovine serum (FBS; Gibco) supplemented with 0.075\% sodium bicarbonate, $50 \mathrm{IU} / \mathrm{ml}$ penicillin-streptomycin. Cells were plated in growth medium in six-well plates and allowed to adhere overnight. The cells were then transfected with DNA ( $3 \mu \mathrm{g} /$ well) of either wild- or mutation-type hPC1-luciferase, using the SuperFect transfection reagent (Qiagen) according to the manufacturer's protocol. The empty vector, pGL2-basic plasmid, was similarly transfected as a control. The medium was changed to DMEM serum-free medium for overnight incubation, and cells were treated with $\mathrm{T}_{3}\left(10^{-8}\right.$ $\mathrm{M}$ ), or 9-cis-retinoic acid (9-cis-RA, $10^{-7} \mathrm{M}$ ) or all-trans-retinoic acid (all-trans-RA, $10^{-7} \mathrm{M}$ ) for $16 \mathrm{~h}$ and harvested in lysis buffer (Promega). Cell lysates were analyzed for luciferase activity using the dual-luciferase reporter assay system (Promega) following the manufacturer's protocol. This kit controls for transfection efficiency.

\section{RNA extraction and quantitative real-time reverse transcription (RT)-PCR}

Total RNA was extracted from tissue using the RNAwiz reagent (Ambion, Inc., Austin, TX, USA), following the manufacturer's protocol. To amplify PC1 and GAPDH cDNA, upstream and downstream primers were designed based on published cDNA sequences (Bloomquist et al. 1991, Winer et al. 1999). The sequences of the primers were as follows: $5^{\prime}$-agatcccgaagaagtgctc-3' (PG1-5'), $5^{\prime}$-ctcttggaactgaacgttttc-3' (PC1-3'), 5'-tgcaccaccaa ctgcttag- $3^{\prime}$ (GAPDH-5') and 5'-ggatgcagggatga tgttc- $3^{\prime}$ (GAPDH-3').

Quantitative measurement of PG1 and GAPDH cDNA using total RNA was performed by QuaniTect SYBR Green RT-PCR kit according to the manufacturer's instructions (Qiagen). The real-time cycler conditions were as follows: reverse transcription at $50{ }^{\circ} \mathrm{C}$ for $30 \mathrm{~min}$ and after denaturation at $95^{\circ} \mathrm{C}$ for $15 \mathrm{~min}$, the cDNA products were amplified with 40 cycles, each cycle consisting of denaturation at $95^{\circ} \mathrm{C}$ for $15 \mathrm{~s}$ and annealing/extension at $58{ }^{\circ} \mathrm{C}$ for $1 \mathrm{~min}$. The accumulating DNA products were monitored by the iCycler iQ optical system (BioRad), with the data being stored continuously during the reaction. Product purity was confirmed by dissociation curve analysis and agarose gel electrophorsis in the presence of ethidium bromide. The calculations of the initial mRNA copy numbers in each sample were made according 
to the cycle threshold $\left(\mathrm{C}_{\mathrm{T}}\right)$ method (Livak \& Schmittgen 2001).

\section{Labeling of cRNA probes and in situ hybridization}

For in situ hybridization, a construct containing bases 65 to 556 of rat PC1 (Bloomquist et al. 1991) in pBluescipt II SK-vector (Strategene, La Jolla, CA), a generous gift from Richard Mains (now at University of Connecticut) was used. Antisense and sense RNA probes were generated by transcription with T3 and T7 RNA polymerase, with a DIG RNA labeling kit (Roche). In situ hybridization was performed as previously described (Shen et al. 1997) with slight modifications. Briefly, sections were deparaffinized with xylene, digested with proteinase $\mathrm{K}$, post-fixed with $4 \%$ paraformaldehyde, washed in phosphate buffer and treated with $0 \cdot 2 \mathrm{M} \mathrm{HCl}$. The sections were hybridized overnight at $42{ }^{\circ} \mathrm{C}$ and then treated with ribonuclease $\mathrm{A}$ for $30 \mathrm{~min}$. In situ hybridization signals were detected immunohistochemically with alkaline phosphataseconjugated anti-DIG antibody according to the manufacturer's instructions (DIG nucleic acid detection kit; Roche).

\section{Electropheretic mobility shift assays (EMSAs)}

EMSAs were performed as described previously $(\mathrm{Li}$ et al. 2001), using double-stranded oligonucleotide probes corresponding to the hPCl promoter sequence from -20 to $+30 \mathrm{bp}$ (wild-type, $\mathrm{Wt}$ ), and thyroid hormone receptor element deletion mutations (TRE Mut), and were radiolabeled using $\left[\gamma^{-32} \mathrm{P}\right]$ ATP $(6000 \mathrm{Ci} / \mathrm{mmol}, \quad$ ICN; MP Bopmedicals, Aurora, OH, USA) and $\mathrm{T}_{4}$ polynucleotide kinase. EMSA reactions were incubated with purified TR $\alpha 1(0.5 \mu \mathrm{g}$, Santa Cruz Biotechnology, Santa Cruz, CA, USA), or RXR $\beta(0.5 \mu \mathrm{g}$, Biomol, Plymouth Meeting, PA, USA) proteins in reaction buffer $(25 \mathrm{mM}$ HEPES, $0.5 \mathrm{mM}$ EDTA, $50 \mathrm{mM} \mathrm{KCl}, 10 \%$ glycerol, $0.5 \mathrm{mM}$ dithiothreitol, $0.5 \mathrm{mM}$ phenylmethyl sulfonyl fluoride and $2 \mu \mathrm{g}$ poly di-dC) for $10 \mathrm{~min}$ on ice and subsequently, the incubation was continued with radiolabeled DNA probes for $30 \mathrm{~min}$. For antibody supershift experiments, specific antibodies were added to mixtures 10 min after the addition of the radiolabeled DNA probes. Protein-DNA complexes were analyzed on $6 \%$ polyacrylamide gels that were run using
$25 \mathrm{mM}$ Tris, $190 \mathrm{mM}$ glycine and $1 \mathrm{mM}$ EDTA buffer, and were visualized by autoradiography.

\section{Nuclear extract preparation and EMSAs}

Nuclear extracts were prepared from GH3 cells according to Dignam (1990). Protein concentrations in nuclear extracts were determined by BioRad protein assay kit. EMSAs were performed as described above using $0.5 \mu \mathrm{g}$ GH3 nuclear proteins.

\section{Results}

\section{Changes in PC1 mRNA expression in rat hypothalamus, hippocampus and cortex by thyroid status}

We previously showed that rat anterior pituitary PC1 mRNA levels are increased in hypothyroidism and reduced in hyperthyroidism, compared with euthyroid levels ( $\mathrm{Li}$ et al. 2001). We now sought to understand whether PC1 mRNA was similarly regulated in important neuropeptide-rich brain regions, such as the hypothalamus, cortex and hippocampus. In the current study, rats were made hypothyroid and hyperthyroid by a 3-week procedure slightly modified from our previous protocol (Li et al. 2001); hypothyroidism was induced using low-iodine/PTU chow instead of drinking water containing PTU, and hyperthyroidism was induced by the implantation of sustained-release $\mathrm{T}_{4}$ pellets instead of injection of $\mathrm{T}_{3}$. The hypothyroidism of PTU-treated rats was confirmed by demonstrating increased plasma TSH levels $(P<0 \cdot 0001)$, and the hyperthyroidism of $\mathrm{T}_{4}$-treated rats was confirmed by demonstrating decreased plasma TSH levels $(P<0 \cdot 005)$ (Fig. 1A). There was no overlap in TSH levels between the euthyroid and hypothyroid animals or between the euthyroid and hyperthyroid animals.

PC1 mRNA (determined by real-time PCR) increased significantly in the hypothalamus $(P<0 \cdot 005)$ and cerebral cortex $(P<0 \cdot 05)$ of hypothyroid rats compared with euthyroid animals (Fig. 1B). In contrast, no differences were detected in the mRNA levels of PG1 in hippocampus between hypothyroid and control rats $(P=\mathrm{NS})$. On the other hand, in hyperthyroid rats, PC1 mRNA levels were significantly down-regulated in hypothalamus and cerebral cortex by $\mathrm{T}_{4}$ compared with euthyroid 

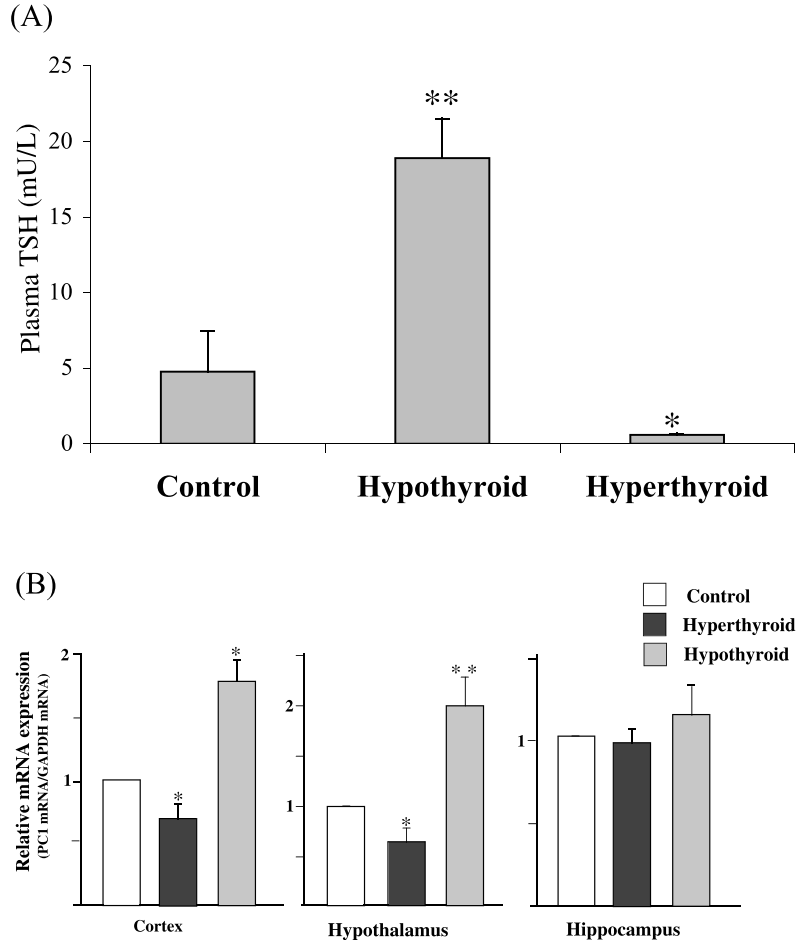

Figure 1 (A) Concentrations of plasma TSH in hypothyroid and hyperthyroid rats. Plasma TSH levels were measured by RIA. The data are represented as the means \pm S.E.M. ( $n=6 /$ group). ${ }^{\star} P<0.005$ vs control; ${ }^{* *} P<0.0001$ vs control. (B) Cortical, hypothalamic and hippocampal PC1 mRNA levels in hyperthyroid and hypothyroid rats as determined by real-time RT-PCR for each individual animal and corrected for GAPDH expression. Results are means \pm S.E.M. ( $n=5 /$ group). ${ }^{\star} P<0.05 ;{ }^{\star *} P<0.005$.

animals $(P<0 \cdot 05)$. However, no significant change was detected in mRNA levels of PCl in the hippocampus between hypothyroid and euthyroid rats $(P=\mathrm{NS})$. These data indicate that there are brain region differences in thyroid hormone responsiveness for $\mathrm{PC} 1$.

\section{Localization of PC1 mRNA expression in the rat hypothalamus, cortex and hippocampus}

Thyroid hormones are essential for controlling a variety of metabolic and developmental processes, in particular brain regions (Bernal 2002). To determine the localization of PG1 mRNA in rat neuropeptide-rich brain regions, we used in situ hybridization with a non-radioactive cRNA probe to localize thyroid hormone regulation of $\mathrm{PC} 1$ expression in more detail (Fig. 2). Using a sense probe, no hybidization signal was detected in hypothalamus (Fig. 2A), cortex (Fig. 2B) or hippocampus (Fig. 2C). Using an antisense probe, PG1 was clearly present in the granular layer of CA1, CA2 and CA3 and dentate gyrus (DG) of hippocampus (Fig. 2E), but no significant mRNA level changes occurred between the three groups. We found that in the cerebral cortex, PG1 mRNA was highly expressed in the retrosplenial (RS) agranular cortex and was abundant in the whole cerebral cortex region, including the motor cortex (M), auditory cortex, and somatosensory cortex (S) (Fig. 2E). Compared with control rats, in situ hybridization of the PTU-treated hypothyroid rats and the $\mathrm{T}_{4}$-treated hyperthyroid rats demonstrated a similar pattern in rat brain cerebral cortex, however the hypothyroid rats had higher expression than the control rats and the $\mathrm{T}_{4}$-treated rats had lower expression than the control rats (Fig. 2E, F and G). Additionally, PG1 mRNA expression in the hypothalamus was found in periventricular $(\mathrm{Pe})$, paraventricular $(\mathrm{Pa})$, and medial preoptic (MPO), as well as in the lateral preoptic (LPO) area, with the highest concentrations in the basal hypothalamus (Fig. 2H). Although similar PC1 mRNA expression patterns were found in the three groups, the expression levels of PC1 were higher in hypothyroid and lower in hyperthyroid rats (Fig. $2 \mathrm{H}, \mathrm{I}$ and $\mathrm{J}$ ).

\section{$\mathrm{T}_{3}$ and 9-cis-RA regulation of $\mathrm{hPC} 1$ promoter activity through two nTREs}

We previously performed transient transfection assays in GH3 cells using a series of deletion hPG1 promoter constructs in the presence and absence of $\mathrm{T}_{3}$ and reported that the minimal construct -82 to + 19 bp exhibited both basal luciferase activity and down-regulation by $\mathrm{T}_{3}$ (Li et al. 2001). We detected two TRE-like half-sites, which we named nTRE1 and nTRE2 in this region of the promoter. With the mutation of the central two and three nucleotides of two putative nTREs, the inhibition by $\mathrm{T}_{3}$ treatment was only partially abolished using these mutated promoters ( $\mathrm{Li}$ et al. 2001). These results led us to hypothesize that the $\mathrm{T}_{3}$ inhibitory effect may involve more than these two TRE-like half-sites, and proposed that this region contains multiple TRE-like half-sites or other response elements that are directly or indirectly regulated by $\mathrm{T}_{3}$ and which function in concert to mediate $\mathrm{T}_{3}$ 


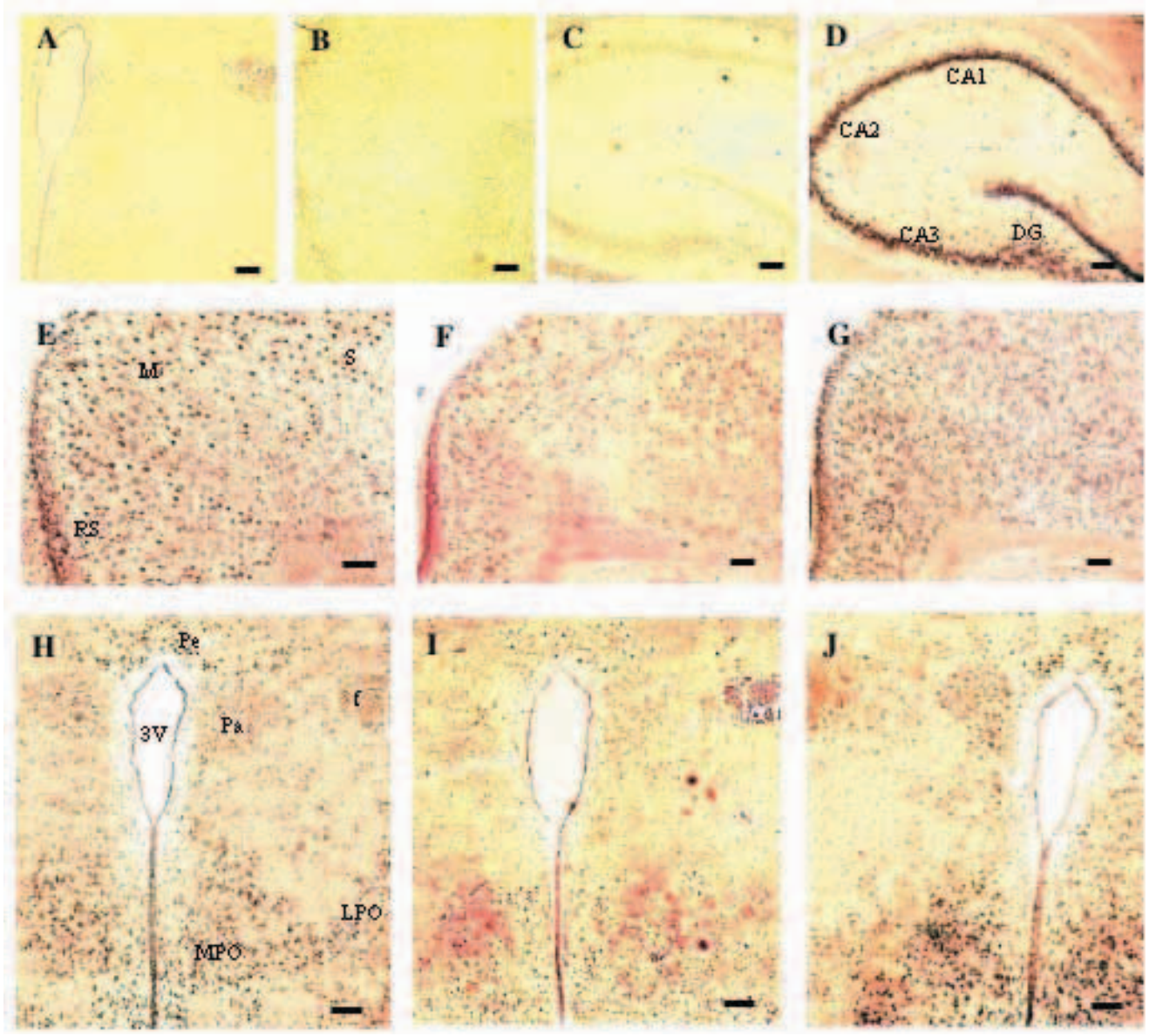

Figure 2 In situ localization of PC1 mRNA in rat brains of hyperthyroid, hypothyroid and euthyroid rats using non-radioactive DIG-labeled cRNA probes. (A, B and C) Hybridization with a sense PC1 cRNA probe in control rat hypothalamus (A), cortex (B) and hippocampus (C). (D) Hybridization with an antisense PC1 cRNA probe in control hippocampus (C). (E, F and $\mathrm{G}$ ) Hybridization with an antisense PC1 CRNA probe in control cerebral cortex (E), $\mathrm{T}_{4}$-treated rat cortex $(\mathrm{F})$ and $\mathrm{PTU}$-treated rat cortex $(\mathrm{G})$. $(\mathrm{H}, \mathrm{I}$ and $\mathrm{J})$ Localization on PC1 mRNA in control rat hypothalamus $(\mathrm{H}), \mathrm{T}_{4}$-treated rat hypothalamus (I), PTU-treated rat hypothalamus (J). Abbreviations: Pe, periventricular hypothalamic nucleus; $\mathrm{Pa}$, paraventricular hypothalamic nucleus; MPO, medial preoptic area; $3 \mathrm{~V}$, third ventricle; f, fornix; LPO, lateral preoptic area; CA1, 2 and 3, field CA of hippocampus; RS, retrosplenial granular cortex; M, motor cortex; S1, primary somatosensory cortex. Scale bars, $100 \mu \mathrm{m}$.

regulation. To directly study this hypothesis, in the next series of experiments, we tested the regulation by $\mathrm{T}_{3}, 9$-cis-RA or all-trans-RA of hPCl promoter construct -82 to +216 bp (higher promoter activity was present with this construct compared with using -82 to $+19 \mathrm{bp}$ ) with either the nTRE1 or nTRE2 intact or deleted (Fig. 3A). 9-cis-RA binds primarily to the RXR, while all-trans-RA binds primarily to the retinoic acid receptor (RAR). Because mutations in the central nucleotide core of the two nTREs still led to significant negative regulation by $\mathrm{T}_{3}$ (Li et al. 2001), it was deemed necessary to delete regions of the promoter containing either nTRE1 and nTRE2, or both, in order to understand the relative contributions of each of these nTREs. Transfection of a construct with deletion of nTRE1 (PG1 Mut1) or nTRE2 (PG1 Mut2) alone showed substantial promoter activity, but there was still significant $\mathrm{T}_{3}$ inhibition of hPCl promoter luciferase activity (Fig. 3B; $P<0 \cdot 05)$. However, transfection of a construct with deletion of both the nTRE1 and nTRE2 region 
(A)

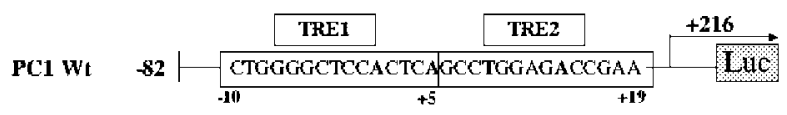

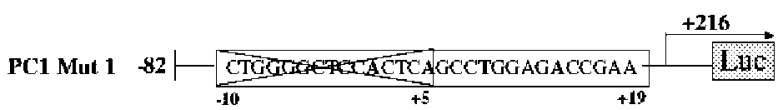

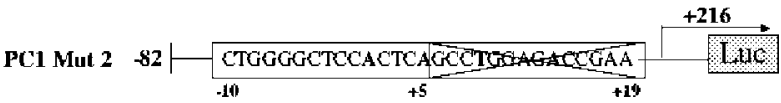

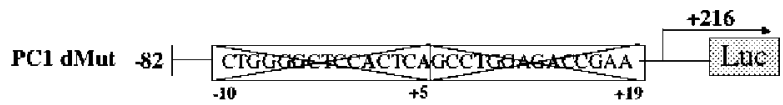

(C)

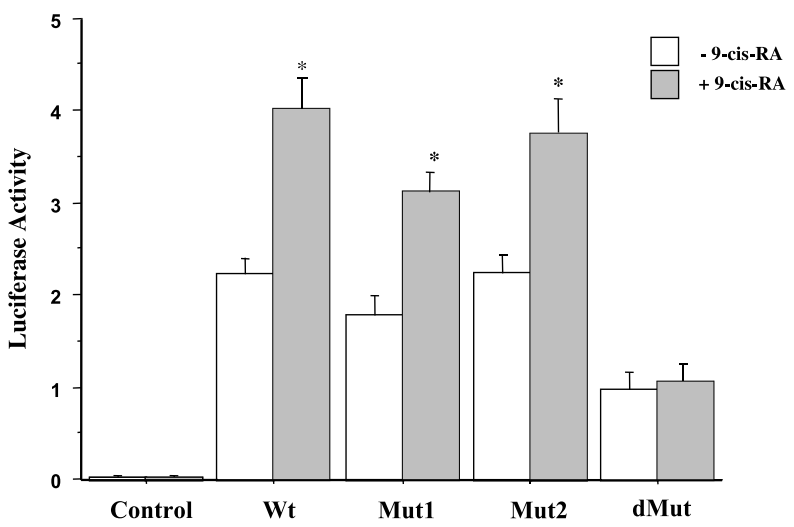

(B)

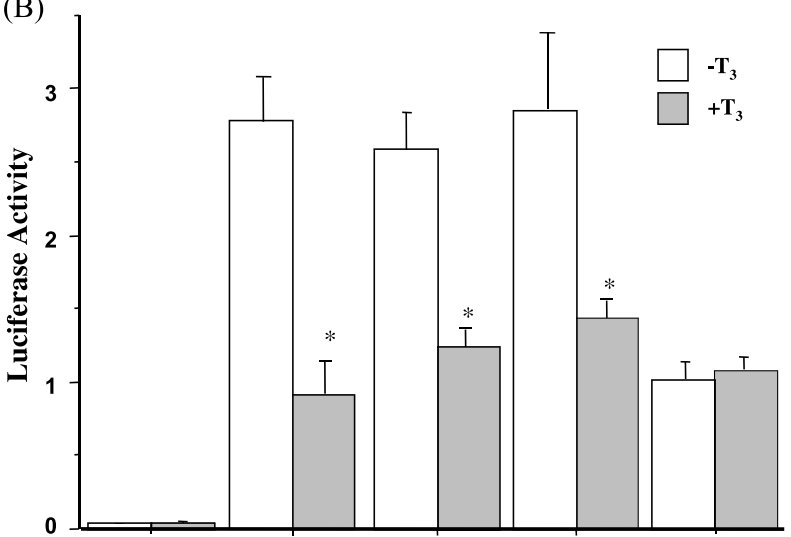

(D)

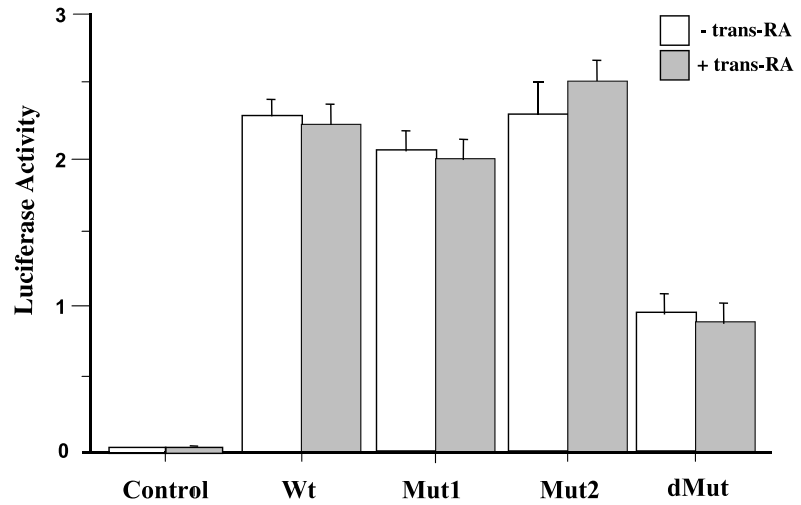

Figure 3 Effect of $\mathrm{T}_{3}, 9$-cis-RA and all-trans-RA on wild-type or deleted mutant human PC1 promoter (hPC1). (A) Schematic representations of hPC1 luciferase constructs $(-82$ to +216$)$ wild-type (PC1 Wt), deletion mutant TRE1 (PC1 Mut1), deletion mutant TRE 2 (PC1 Mut2), and double-mutant TRE 1 and TRE 2 (PC1 dMut). (B) GH3 cells transfected with Wt or Mut hPC1 promoter luciferase construct and treated with or without $\mathrm{T}_{3}\left(10^{-8} \mathrm{M}\right)$ for $24 \mathrm{~h}$. The data from triplicate measurements are expressed as means \pm S.E.M. ${ }^{*} P<0.05$ vs without $T_{3}$. (C) GH3 cells transfected with Wt or Mut hPC1 promoter luciferase construct and treated with or without 9-cis-RA $\left(10^{-7} \mathrm{M}\right)$ for $24 \mathrm{~h}$. The data from triplicate measurements are expressed as means \pm S.E.M. ${ }^{*} P<0.05$ vs without 9 -cis-RA. (D) GH3 cells transfected with Wt or Mut hPC1 promoter luciferase construct and treated with or without all-trans-RA (10 $\left.{ }^{-7} \mathrm{M}\right)$ for $24 \mathrm{~h}$. The data from triplicate measurements arer expressed as means \pm S.E.M.

(PC1 dMut) showed significant promoter activity, yet absence of inhibition by $\mathrm{T}_{3}$ treatment $(P=\mathrm{NS})$. This indicates that the $\mathrm{T}_{3}$ inhibitory effect involves multiple regions in this part of the promoter, more than the two discrete nTREs identified in our previous study.

In contrast to $\mathrm{T}_{3}$ treatment, 9-cis-RA treatment resulted in 2-fold stimulation of the wild-type hPG1 promoter when transfected into GH3 cells (Fig. 3C; $P<0.05)$. Using the same single-region deletion constructs, significant stimulation by 9-cis-RAtreated promoter activity using both PG1 Mutl or PC1 Mut2 constructs was still observed $(P<0 \cdot 05)$, in a pattern similar to the stimulation using the wild-type construct. But when both the nTRE1 and nTRE2 regions were deleted (PG1 dMut), 9-cis-RA stimulation was completely abolished $(P=\mathrm{NS})$. These data indicate that the full nTRE1 and nTRE2 regions of the hPG1 promoter contain important cis-acting DNA elements for negative regulation by $\mathrm{T}_{3}$ and positive regulation by 9-cis-RA and this full region is involved in the transcriptional regulation of this important target gene.

On the other hand, when all-trans-RA $\left(10^{-7} \mathrm{M}\right)$ was added to $\mathrm{PC} 1$-promoter $(-82 /+216$ bp region 
(A) Wt : ${ }_{-20}$ CTGGGAAGGGCTGGGGCTCCACTCAGCCTGGAGACCGAAGCGCTTCACT+29 Mut 1: $\quad{ }_{-2}$ CTGGGAAGGGGCCTGGAGACCGAAGCGCTTCACT +29 Mut 2: ${ }_{-20}$ CTGGGAAGGGCTGGGGCTCCACTCAGCGCTTCACT $_{+29}$ dMut: ${ }_{-20}$ CTGGGAAGGGGCGCTTCACT $_{+29}$

(B)
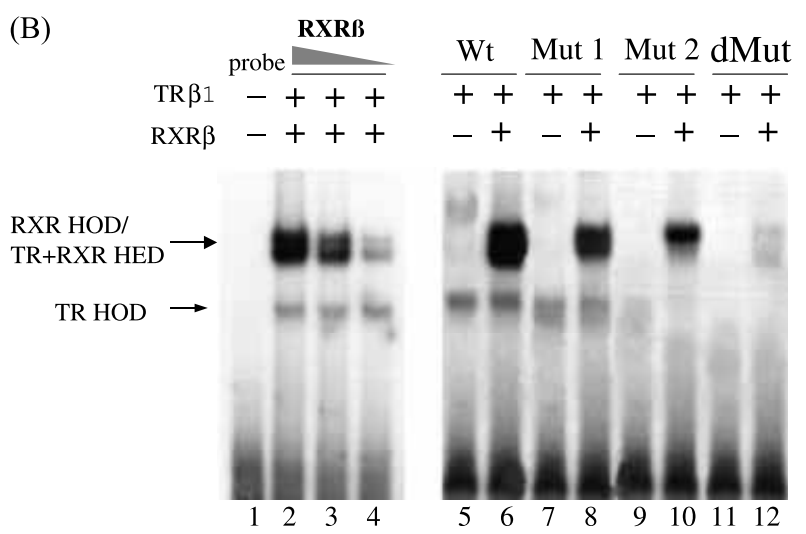

(C)

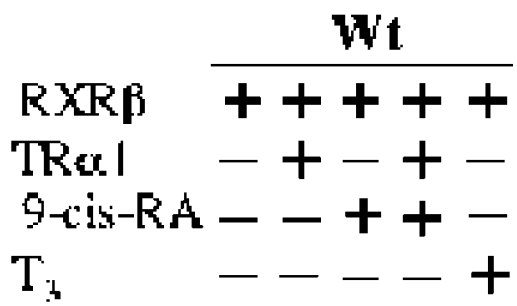

RXR HODi $\mathrm{TR}+\mathrm{RXR}$ HED

(D)

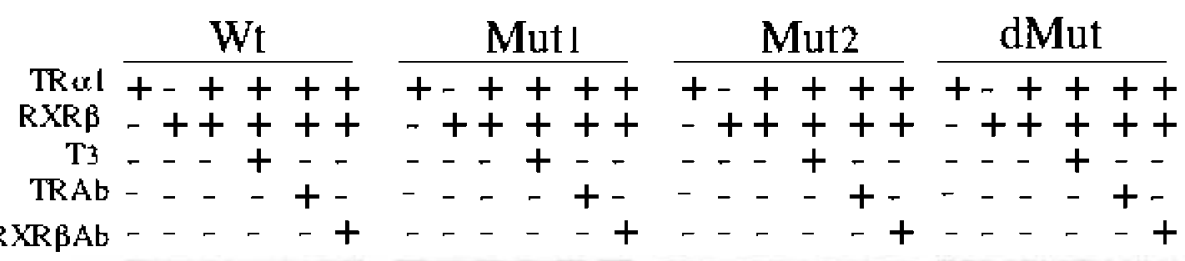

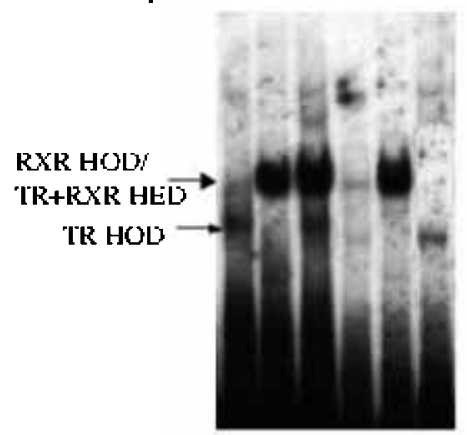

123456

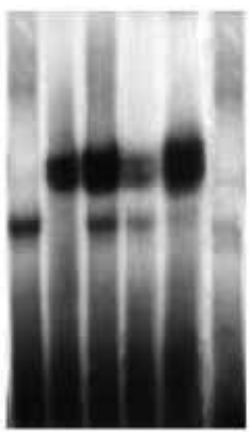

789101112

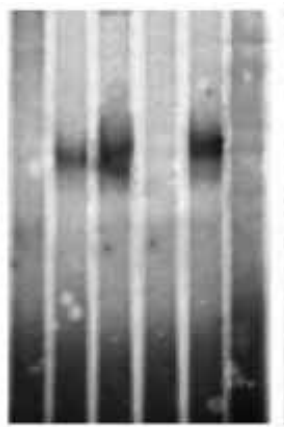

131415161718192021222324 
of the hPC1 promoter)-transfected GH3 cells, no stimulatory effects were noted (Fig. 3D). These results indicate that RAR does not interact with this region of the $\mathrm{PCl}$ promoter.

\section{EMSAs using wild-type and mutant oligonucleotides with TR $\alpha 1$ and $R X R \beta$ proteins}

To further determine whether the TR/RXR binding sites of the hPC1 promoter act as a unique region interacting with the $\mathrm{TR} \alpha 1$ and $\operatorname{RXR} \beta$ proteins, and if $\mathrm{T}_{3}$ can cause a change in protein binding to these regions, we performed EMSA experiments using this region of the $\mathrm{PC} 1$ promoter. The EMSAs were performed using a series of radiolabeled oligonucleotides probes. The wild-type (Wt) oligonucleotide probe contained sequences from -20 to $+29 \mathrm{bp}$ of the PGl promoter, which contain both nTRE1 and nTRE2. The deleted mutant-type 1 (Mutl) oligonucleotide probe contained sequences from -20 to $+29 \mathrm{bp}$ of the PG1 promoter without sequences from -10 to +5 . The deleted mutant-type 2 (Mut2) oligonucleotide probe contained sequences from -20 to $+29 \mathrm{bp}$ of the PC1 promoter without sequences from +6 to +19 . The deleted double-mutant (dMut) oligonucleotide probe contained sequences from -20 to $+29 \mathrm{bp}$ of the PG1 promoter without sequences from -10 to +19 (Fig. 4A). In all experiments, the amount of probe added to each lane was normalized by the number of counts. When TR $\alpha 1$ was added to the reactions with $\mathrm{Wt}$ PCl probe, predominantly a TR homodimer was formed as indicated by the smaller arrow in Fig. 4B (lane 5). Addition of both TR $\alpha 1 / \mathrm{RXR} \beta$ proteins to the $\mathrm{Wt}$ PG1 probe resulted in strongly binding complex (larger arrow) consisting of an RXR homodimer and a TR plus RXR heterodimer (lane 6). It is noteworthy that the effects of RXR were much stronger in the current paper than in our prior publication ( $\mathrm{Li}$ et al. 2000, 2001), which we postulate may reflect a difference in protein preparation supplied by the company. The intense TR/RXR complex was reduced with decreasing amounts of RXR added in a dose-dependent manner (lanes 2-4). As expected, homodimer binding between the wild-type probe and TR was not affected by the dose of RXR (lanes 2-4). In contrast to the Wt probe, the Mutl probe exhibited substantially decreased TR/RXR complex binding and mildly decreased TR homodimer binding (the same number of counts of each probe were added to each lane) (lanes 7-8) compared with the $\mathrm{Wt}$ probe. The Mut2 probe exhibited essentially no TR homodimer binding and substantially decreased TR/RXR complex binding (lanes 9-10) compared with the Wt probe (lanes 5-6). We observed that the dMut did not form specific protein complexes with either TR alone or TR plus RXR (lanes 11 and 12) (see Fig. 4D, lanes 22-24, which demonstrates that the faint binding in the heterodimer region with the dMut is not specific).

To confirm the specificity of the interactions between the RXR protein and the PG1 promoter probe, we tested the effect of 9-cis-RA and $\mathrm{T}_{3}$ using EMSAs. As shown in Fig. 4C, 9-cis-RA increased the binding of $\operatorname{RXR} \beta$ alone to the $\mathrm{PCl}$ probe (compare lane 3 with lane 1). Similarly, 9-cis-RA increased the binding of RXR $\beta$ plus TR to the PG1 probe (compare lane 4 with lane 2). In contrast, $\mathrm{T}_{3}$ did not affect the binding of $\operatorname{RXR} \beta$ to the $\mathrm{PG} 1$ probe (compare lane 5 with lane 1 ). These results confirm the specificity of the binding between RXR and the PG1 promoter and agree nicely with our studies showing 9-cis-RA increases PC1 promoter activity (Fig. 3C).

To test if the binding of the TR/RXR proteins to the PGl promoter probe was specific, we examined the effects of $\mathrm{T}_{3}$ or $\mathrm{TR}$ or RXR antibodies on the protein-probe complex (Fig. 4D). As can be seen in lanes 1 and 2, both TR (small arrow) and RXR (large arrow) form homodimer bands with the $\mathrm{Wt}$ probe, with stronger binding using RXR compared with TR. The band complex (indicated by the larger arrow) most probably represents binding of an RXR homodimer and a TR plus RXR heterodimer to the probe. The addition of $\mathrm{T}_{3}$ to the $\mathrm{Wt}$ probe in the presence of

Figure 4 Binding of TR $\alpha 1$ and RXR $\beta$ proteins to wild-type (Wt) and mutant (Mut) oligonucleotides. (A) Sequences of Wt and Mut oligonucleotide. (B) EMSAs using purified TR $\alpha 1$ and RXR $\beta$ proteins binding to Wt and mutant probes. Components of the EMSAs are indicated at the top of the figure. (C) Effect of 9-cis-RA and $T_{3}$ on EMSAs using purified TR $\alpha 1$ and $R X R \beta$ proteins binding to the Wt hPC1 probe. (D) Effect of $T_{3}$ and RXR $\beta A b$ and TRAb on EMSAs using purified TR $\alpha 1$ and $R X R \beta$ proteins binding to Wt and mutant probes. Components of the EMSAs are indicated at the top of the figure. 
TR plus RXR caused a dramatic reduction in this complex (Fig. 4D, lane 4). The addition of anti-TR $\alpha$ antibody (TRAb) reduced the TR homodimer band, but had little effect on the complex (lane 5), while the addition of anti-RXR $\beta$ antibody (RXRAb) reduced the complex band of TR plus RXR (lane 6). As indicated in Fig. 4D, lanes $7-12$, the binding of the Mutl probe to TR, RXR or TR plus RXR revealed quite similar binding patterns compared with the Wt probe. The addition of the Mut2 probe also revealed similar but substantially reduced binding (lanes 13-18) compared with the Wt. However, the dMut probe failed to exhibit specific TR or RXR homodimer binding, or heterodimer complexes (lanes 19-24). Thus, from these EMSA experiments, we conclude that both TR and RXR bind more strongly to the nTRE2 region than to the nTRE1 region, but TR and RXR are capable of some binding to both these regions, which is absent in the double mutation. These results indicate that the TR/RXR binding sites of the hPCl promoter involve both regions containing the nTREs, which both act in concert to mediate $\mathrm{T}_{3}$ and $\mathrm{RXR}$ regulation. Thus, both our transfection experiments and our EMSA data support the finding that both broad regions in the hPCl promoter are needed to exert the full negative effect of $\mathrm{T}_{3}$ and the positive effect of 9-cis-RA.

\section{EMSAs using PC1 promoter oligonucleotide with GH3 nuclear extracts}

In order to confirm that the binding of the wild-type oligonucleotide hPGl promoter with purified $\mathrm{TR} \alpha \mathrm{l}$ and $\mathrm{RXR} \beta$ proteins reflects the binding within GH3 cells, we performed EMSAs using GH3 cell nuclear extracts to the PG1 promoter probe. As shown in Fig. 5, a complex that probably represents binding of an RXR homodimer and a TR plus RXR heterodimer to the probe was observed (lane 2). This binding (primarily the lower band of the complex) was decreased with the addition of $\mathrm{T}_{3}$ (lane 3) and increased by the addition of 9-cis-RA (lane 5). TRal (lane 4) and RXR (lane 6) antibody diminished the intensity of the complex and caused the appearance of a less mobile band complex (supershift). These results confirm the specificity of binding to TR and RXR proteins in GH3 nuclear extracts.

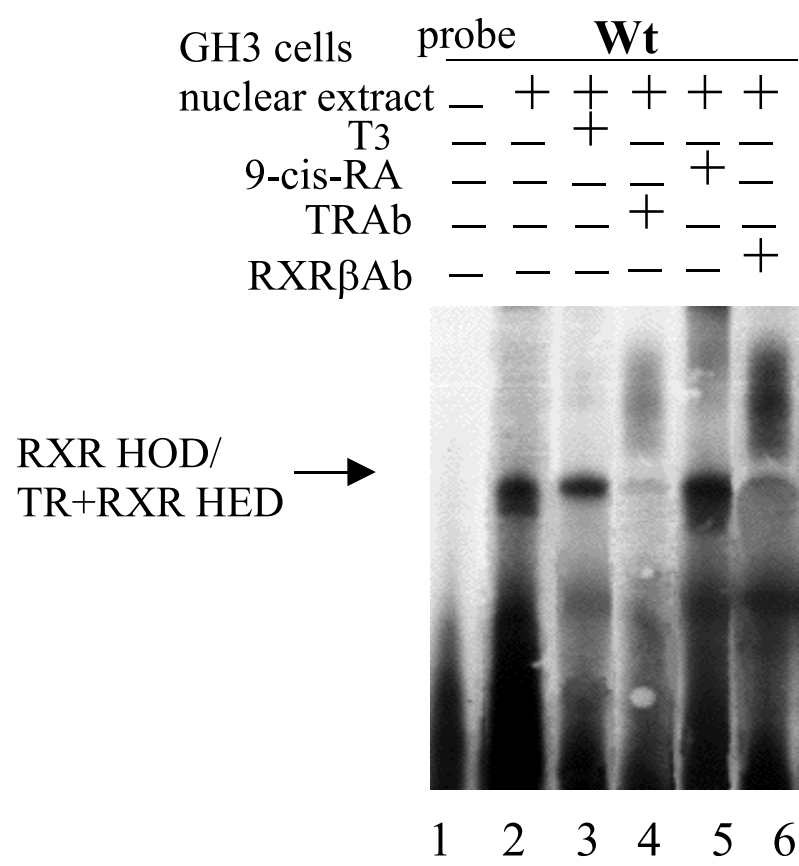

Figure 5 The binding of the $\mathrm{GH} 3$ nuclear extracts to the Wt hPC1 probe. The effect of $\mathrm{T}_{3}$ and 9-cis-RA as well as RXR $\beta A b$ and TRAb on EMSAs using GH3 nuclear extracts is shown.

\section{Discussion}

PG1, as a member of the prohormone convertases family, is an important processing enzyme which usually makes the earlier cleavages of prohormones (Zhou et al. 1993). In combination with PC2, which often makes the later cleavages, PC1 expression determines the ratio of many inactive prohormone precursors to active hormones ( $\mathrm{Li}$ et al. 1999, Nie et al. 2000). Baseline expression of PC1 and PC2 in various brain regions has been well studied (Schafer et al. 1993, $\mathrm{Pu}$ et al. 1996), but regulation of expression of PG1 and PG2 following various pharmacological manipulations has been limited to the pituitary. Schafer et al. (1993), using in situ hybridization, found that in general, PC2 was more widely expressed than PC1 in the central nervous system (CNS), although many regional variations were detected. The finding that some brain regions express PC1, some express PC2 and some express both convertases (Schafer et al. 1993) suggests that PC1 and PC2 may act both independently and in combination for the activation of neuropeptides in important brain regions. In the present study, we found that basal brain expression of PG1 was of a 
similar pattern to that reported by Schafer et al. (1993). We then demonstrated that PTU-induced hypothyroidism stimulated, and $\mathrm{T}_{4}$-induced hyperthyroidism suppressed, PC1 mRNA expression in the rat hypothalamus and cerebral cortex, as measured by real-time PCR and localized by in situ hybridization. The regulation was specific to certain brain regions, as we did not detect regulation by thyroid hormone status in the hippocampus. These results led us to postulate that the regulation of PG1 by thyroid hormone would be expected to alter levels of bioactive neuropeptides in important brain regions and may explain some of the profound central effects of altered thyroid hormone status. In another study, we have found that thyroid hormone treatment regulates PC1 and PC2 protein expression in various brain regions in a similar manner as the gene expression described here (Shen et al., unpublished observations). This leads to blunted proTRH processing in selective brain regions of hyperthyroid rats and increased proTRH processing in hypothyroid rats (Shen et al., unpublished observations).

Thyroid hormones are essential for mammalian growth and development. They also exert specific effects on several organ systems, including cardiovascular, reproductive, central and peripheral nervous systems (Herman-Bonert \& Friedman 2001). A number of studies have indicated that thyroid hormones have important physiological functions, not only during brain maturation, but also in the adult vertebrate brain (Bernal 2002). Multiple genes in the CNS are regulated by thyroid hormone status (Anderson et al. 2000). One example is the neuronal gene, RC3, whose expression was influenced by early neonatal hypothyroidism as well as thyroid hormone treatment in adult rat brain (Iniguez et al. 1992). Additionally, chronic thyroxine treatment downregulated the noradrenergic cyclic AMP generating system in rat cerebral cortex (Schmidt \& Schultz 1985). Thus, our finding that thyroid hormone status regulates $\mathrm{PCl}$ expression in brain regions is consistent with the effects of thyroid status on the expression of other genes.

Thyroid hormone facilitation of brain development is based on the assumption that thyroid hormone action proceeds along a nuclear pathway generally similar to that operating in other tissues (Oppenheimer \& Schwartz 1997). TRs bind to the TREs located upstream from the promoters of target genes to regulate their expression transcriptionally (Harvey \& Williams 2002). In most cases, TRs are transcriptional repressors in the absence of their cognate hormone $\left(T_{3}\right)$ and are turned into activators upon ligand binding (Zhang \& Lazar 2000). We previously identified two potential nTRE half-sites on the PGl promoter $(\mathrm{Li}$ et al. 2001). Mutation of the core two nucleotides of these half-sites still leads to significant negative regulation of PC1 promoter activity by $T_{3}$. We hypothesized that the negative transcription mediated by $\mathrm{T}_{3}$ on this region thus involves more than the two putative nTRE half-sites, and may also involve the activation of co-repressors or the suppression of other co-activators.

Recent studies have demonstrated that RXR heterodimerization can augment $\mathrm{T}_{3}$-mediated gene regulation to increase TR/DNA interactions (Force et al. 1994, Harbers et al. 1996). However, the magnitude of the augmentation varies significantly, especially when different cell lines were used. Both 9-cis-RA and $\mathrm{T}_{3}$-stimulated $\mathrm{rGH}$ promoter, and the combination of $\mathrm{T}_{3}$ and 9-cis-RA exerted additive effects on this promoter in GH3 cells (Li et al. 2001). In our study, using the hPG1 promoter transiently transfected into GH3 cells, we found that $\mathrm{T}_{3}$ negatively regulated hPCl promoter activity, while 9-cis-RA stimulated the activity, indicating that binding to RXR abrogates, rather than augments the effects of $\mathrm{T}_{3}$ on TR. All-trans-RA had no effect on promoter activity indicating that RAR does not interact with this region of the $\mathrm{PCl}$ promoter.

In our previous study, after mutation of the central two and three nucleotides of the two putative nTREs, substantial residual inhibition by $\mathrm{T}_{3}$ was found. These results led us to hypothesize that the $\mathrm{T}_{3}$ inhibitory effect may involve more than these two TRE-like half-sites, and proposed that this region contains multiple sites which either directly or indirectly mediate $\mathrm{T}_{3}$ regulation. In the present study, deletional analysis of hPGl promoter constructs in transient transfection assays coupled with EMSAs demonstrate that the broad region from -10 to $+19 \mathrm{bp}$ of the hPGl promoter is probably responsible for the negative regulation by $\mathrm{T}_{3}$. However, the fact that deletion of nTRE2 in the EMSAs (Fig. 4B) led to the most dramatic decrease in binding to both TR and RXR provides evidence that the region between +5 and +19 on the hPCl promoter is most crucial for binding to TR and RXR. This region is near the TSS, similar 
to the observation for nTREs described by others (Satoh et al. 1996). Transcriptional repression by $\mathrm{T}_{3}$ can occur by binding of $\mathrm{TRs}$ to specific nTREs near the TSS to sterically interfere with components of transcription initiation machinery (Oppenheimer \& Schwartz 1997). Although the primary TSS is deleted from the double mutant, it is noteworthy that the double mutant still had greater than 50-fold more activity than the control (promoterless) construct, indicating that the transcriptional machinery is still present in this promoter. This suggests that alternative TSS in the PC1 promoter can be used, as suggested by Jansen et al. (1995).

The fact that in the double mutant, there was no specific binding to either TR or RXR (the non-specific binding seen in lane 20 and 21 of Fig. 4D was not supershifted by $\mathrm{TR}$ or RXR Ab or reduced by $\mathrm{T}_{3}$ ), provides evidence that there are no other TR or RXR binding sites in this region of the PG1 promoter. Our findings suggest that multiple nuclear factors may be involved in $\mathrm{T}_{3}$ suppression of the hPCl promoter, and indicate that the full nTRE1 and nTRE2 regions of the hPC1 promoter contain important cis-acting DNA elements to recruit transcriptional cofactors (corepressors and coactivators) to the promoter to facilitate transcriptional regulation of the target genes.

In summary, this paper demonstrates that thyroid status regulated PCl expression in the hypothalamus and cortex. These results suggest that this prohormone convertase is involved in neuropeptide precursor processing not only in pituitary, but also in neuropeptide-rich brain regions. We also demonstrated that nTRE2 binds more strongly to TR and RXR than nTRE1, however, both regions exhibit some specific binding. Binding to the PC1 promoter oligonucleotide occurred with GH3 nuclear extracts suggesting that this binding can occur in intact cells. These results indicate that there are multiple elements in this region of the hPGl promoter that TR and RXR interact with either directly or indirectly, and that these regions act in concert in a unique manner to facilitate the negative effect of thyroid hormone on PG1.

\section{Acknowledgments}

We wish to thank Monica Ferrini (Harbor-UCLA Medical Center) for her assistance with interpreting the in situ hybridization results, Richard Mains
(University of Connecticut) for supplying us with the rat PG1 plasmid and Erik Jansen (N.V. Organon, The Netherlands) for supplying us with the PG1 promoter construct.

\section{Funding}

T G F and X S are supported by a Center of Clinical Research Excellence grant (U54 RR14616-01) to Charles R Drew University of Medicine \& Sciences. G A B is supported by Merit Review funds from the Department of Veterans Affairs and NIH Grant CA8936401. This work was also supported by a Thyroid Research Advisory Council (Knoll Pharmaceutical Company) grant SYN-0400-02 to T G F and an RCMI Program grant G21 RR03026-13 to Charles R Drew University of Medicine \& Sciences. There is no conflict of interest that could prejudice the imparitality of this research

\section{References}

Anderson GW, Mariash CN \& Poppenheimer JH 2000 Molecular actions of thyroid hormone. In: Werner and Ingbar's The Thyroid, 8th edn, pp 174-195. Eds LE Braverman \& RD Utiger. Philadelphia: Lippincott-Raven Publishers.

Berman Y, Mzhavia N, Polonskaia A, Furuta M, Steiner DF, Pintar JE \& Devi LA 2000 Defective prodynorphin processing in mice lacking prohormone convertase PC2. Journal of Neurochemistry 75 $1763-1770$.

Bernal J 2002 Action of thyroid hormone in brain. Fournal of Endocrinological Investigation 25 268-288.

Birch NP, Tracer HL, Hakes DJ \& Loh YP 1991 Coordinate regulation of mRNA levels of pro-opiomelanocortin and the candidate processing enzymes PC2 and PC3, but not furin, in the rat pituitary intermediate lobe. Biochemical and Biophysical Research Communications 179 1311-1319.

Bloomquist BT, Eipper BA \& Mains RE 1991 Prohormoneconverting enzymes: regulation and evaluation of function using antisense RNA. Molecular Endocrinology $52014-2024$.

Day R, Schafer MK, Watson SJ, Chretien M \& Seidah NG 1992 Distribution and regulation of the prohormone convertases PCl and PC2 in the rat pituitary. Molecular Endocrinology 6 485-497.

Dignam JD 1990 Preparation of extracts from higher eukaryotes. Methods in Enzymology 182 194-203.

Force WR, Tillman JB, Sprung CN \& Spindler SR 1994 Homodimer and heterodimer DNA binding and transcriptional responsiveness to triiodothyronine (T3) and 9-cis-retinoic acid are determined by the number and order of high affinity half-sites in a T3 response element. Fournal of Biological Chemistry $\mathbf{2 6 9}$ 8863-8871.

Furuta M, Yano H, Zhou A, Rouille Y, Holst II, Carroll R, Ravazzola M, Orci L, Furuta H \& Steiner DF 1997 Defective prohormone processing and altered pancreatic islet morphology in mice lacking active SPC2. PNAS 94 6646-6651.

Harbers M, Wahlstrom GM \& Vennstrom B 1996 Transactivation by the thyroid hormone receptor is dependent on the spacer sequence in hormone response elements containing directly repeated half-sites. Nucleic Acids Research 24 2252-2259. 
Harvey CB \& Williams GR 2002 Mechanism of thyroid hormone action. Thyroid 12 441-446.

Herman-Bonert V \& Friedman TC 2001 The thyroid gland. In: Cecil Essentials of Medicine, 5th edn, pp 555-563. Eds TE Andreoli, CGJ Carpenter, RC Griggs \& J Loscalzo. Philadelphia: WB Saunders Company.

Hodin RA, Lazar MA, Wintman BI, Darling DS, Koenig RJ, Larsen PR, Moore DD \& Chin WW 1989 Identification of a thyroid hormone receptor that is pituitary-specific. Science 244 76-79.

Hooi SC, Koenig JI, Abraczinskas DR \& Kaplan LM 1997 Regulation of anterior pituitary galanin gene expression by thyroid hormone. Brain Research. Molecular Brain Research 51 15-22.

Iniguez MA, Rodriguez-Pena A, Ibarrola N, Morreale de Escobar G \& Bernal J 1992 Adult rat brain is sensitive to thyroid hormone. Regulation of RC3/neurogranin mRNA. Fournal of Clinical Investigation 90 554-558.

Jackson RS, Creemers JW, Ohagi S, Raffin-Sanson ML, Sanders L, Montague CT, Hutton JC \& O'Rahilly S 1997 Obesity and impaired prohormone processing associated with mutations in the human prohormone convertase 1 gene. Nature Genetics 16 303-306.

Jansen E, Ayoubi TA, Meulemans SM \& Van de Ven WJ 1995 Neuroendocrine-specific expression of the human prohormone convertase 1 gene. Hormonal regulation of transcription through distinct cAMP response elements. Fournal of Biological Chemistry 270 15391-15397.

Johnson RC, Darlington DN, Hand TA, Bloomquist BT \& Mains RE 1994 PACE4: a subtilisin-like endoprotease prevalent in the anterior pituitary and regulated by thyroid status. Endocrinology 135 $1178-1185$.

Laurent V, Jaubert-Miazza L, Desjardins R, Day R \& Lindberg I 2004 Biosynthesis of proopiomelanocortin-derived peptides in prohormone convertase 2 and 7B2 null mice. Endocrinology 145 519-528.

Lazar MA 1993 Thyroid hormone receptors: multiple forms, multiple possibilities. Endocrine Reviews 14 184-193.

Li QL, Jansen E \& Friedman TC 1999 Regulation of prohormone convertase 1 (PC1) by gp 130-related cytokines. Molecular and Cellular Endocrinology 158 143-152.

Li QL, Jansen E, Brent GA, Naqvi S, Wilber JF \& Friedman TC 2000 Interactions between the prohormone convertase 2 promoter and the thyroid hormone receptor. Endocrinology 141 3256-3266.

Li QL, Jansen E, Brent GA \& Friedman TC 2001 Regulation of prohormone convertase 1 (PC1) by thyroid hormone. American Fournal of Physiology, Endocrinology and Metabolism 280 E160-170.

Livak KJ \& Schmittgen TD 2001 Analysis of relative gene expression data using real-time quantitative PCR and the 2(-Delta Delta C(T)) method. Methods 25 402-408.

Misiti S, Schomburg L, Yen PM \& Chin WW 1998 Expression and hormonal regulation of coactivator and corepressor genes. Endocrinology 139 2493-2500.

Nie Y, Nakashima M, Brubaker PL, Li Q-L, Perfetti R, Jansen E, Zambre Y, Pipeleers D \& Friedman TC 2000 Regulation of pancreatic PC1 and PC2 associated with increased GLP-1 in diabetic rats. Fournal of Clinical Investigation 105 955-965.

Oppenheimer JH \& Schwartz HL 1997 Molecular basis of thyroid hormone-dependent brain development. Endocrine Reviews 18 $462-475$.

O'Rahilly S, Gray H, Humphreys PJ, Krook A, Polonsky KS, White A, Gibson S, Taylor K \& Carr C 1995 Brief report: impaired processing of prohormones associated with abnormalities of glucose homeostasis and adrenal function. New England fournal of Medicine 333 1386-1390.

Ouafik L, May V, Saffen DW \& Eipper BA 1990 Thyroid hormone regulation of peptidylglycine alpha-amidating monooxygenase expression in anterior pituitary gland. Molecular Endocrinology 4 $1497-1505$
Pu LP, Ma W, Barker JL \& Loh YP 1996 Differential coexpression of genes encoding prothyrotropin-releasing hormone (pro-TRH) and prohormone convertases (PC1 and PC2) in rat brain neurons: implications for differential processing of pro-TRH. Endocrinology 137 1233-1241.

Satoh T, Yamada M, Iwasaki T \& Mori M 1996 Negative regulation of the gene for the preprothyrotropin-releasing hormone from the mouse by thyroid hormone requires additional factors in conjunction with thyroid hormone receptors. Fournal of Biological Chemistry 271 27919-27926.

Schafer MK, Day R, Cullinan WE, Chretien M, Seidah NG \& Watson SJ 1993 Gene expression of prohormone and proprotein convertases in the rat CNS: a comparative in situ hybridization analysis. Fournal of Neurosciences 13 1258-1279.

Schmidt BH \& Schultz JE 1985 Chronic thyroxine treatment of rats down-regulates the noradrenergic cyclic AMP generating system in cerebral cortex. Fournal of Pharmacology and Experimental Therapeutics 233 466-472.

Schneider MJ, Fiering SN, Pallud SE, Parlow AF, St Germain DL \& Galton VA 2001 Targeted disruption of the type 2 selenodeiodinase gene (DIO2) results in a phenotype of pituitary resistance to T4. Molecular Endocrinology 15 2137-2148.

Seidah NG \& Chretien M 1999 Proprotein and prohormone convertases: a family of subtilases generating diverse bioactive polypeptides. Brain Research 848 45-62.

Seidah NG, Marcinkiewicz M, Benjannet S, Gaspar L, Beaubien G, Mattei MG, Lazure C, Mbikay M \& Chretien M 1991 Cloning and primary sequence of a mouse candidate prohormone convertase PG1 homologous to PC2, Furin, and Kex2: distinct chromosomal localization and messenger RNA distribution in brain and pituitary compared to PC2. Molecular Endocrinology $\mathbf{5}$ $111-122$.

Shen X, Minoura H, Yoshida T \& Toyoda N 1997 Changes in ovarian expression of tissue-type plasminogen activator and plasminogen activator inhibitor type-1 messenger ribonucleic acids during ovulation in rat. Endocrine Fournal 44 341-348.

Steiner DF 1998 The proprotein convertases. Current Opinion in Chemical Biology 2 31-39.

Toyoda N, Zavacki AM, Maia AL, Harney JW \& Larsen PR 1995 A novel retinoid $\mathrm{X}$ receptor-independent thyroid hormone response element is present in the human type 1 deiodinase gene. Molecular and Cellular Biology 15 5100-5112.

Winer J, Jung CK, Shackel I \& Williams PM 1999 Development and validation of real-time quantitative reverse transcriptasepolymerase chain reaction for monitoring gene expression in cardiac myocytes in vitro. Analytical Biochemistry 270 41-49.

Zhang J \& Lazar MA 2000 The mechanism of action of thyroid hormones. Annual Review of Physiology 62 439-466.

Zhou A, Bloomquist BT \& Mains RE 1993 The prohormone convertases PC1 and PC2 mediate distinct endoproteolytic cleavages in a strict temporal order during proopiomelanocortin biosynthetic processing. Fournal of Biological Chemistry $\mathbf{2 6 8}$ 1763-1769.

Zhu X, Orci L, Carroll R, Norrbom C, Ravazzola M \& Steiner DF $2002 a$ Severe block in processing of proinsulin to insulin accompanied by elevation of des-64,65 proinsulin intermediates in islets of mice lacking prohormone convertase 1/3. PNAS 99 10299-10304.

Zhu X, Zhou A, Dey A, Norrbom C, Carroll R, Zhang C, Laurent V, Lindberg I, Ugleholdt R, Holst JJ \& Steiner DF $2002 b$ Disruption of PG1/3 expression in mice causes dwarfism and multiple neuroendocrine peptide processing defects. PNAS 99 10293-10298.

\section{Received in final form 10 March 2004 Accepted 30 March 2004}

